\title{
Bio-Diesel Based Additive for Enhancing Flow of Emulsion in Pipeline
}

\author{
Fadairo Adesina, Anawe Paul, Oladepo David, Adeyemi Gbadegesin \\ Covenant University, Ota, Nigeria \\ Email: adesina.fadairo@covenantuniversity.edu.ng, paul.anawe@covenantuniversity.edu.ng, \\ david.oladepo@covenantuniversity.edu.ng,gbadegesin.adeyemi@covenantuniversity.edu.ng
}

Received 14 February 2016; accepted 17 July 2016; published 20 July 2016

Copyright (C 2016 by authors and Scientific Research Publishing Inc.

This work is licensed under the Creative Commons Attribution International License (CC BY).

http://creativecommons.org/licenses/by/4.0/

(c) (i) Open Access

\begin{abstract}
Emulsions are difficult to transport in the oil and gas industry due to its water content and high viscosity property, thus a need arises to break these emulsions down into lighter emulsions that would make it a lot more suitable for transportation. In this research, biodiesel was synthesized and used to break down relatively viscous emulsion samples into lighter emulsion samples. An apparatus was designed with the aim of determining the flowrate of four different samples in different proportions and compositions: $80 \%$ oil and $20 \%$ water (sample $A$ ), $90 \%$ sample $A+10 \%$ of biodiesel by volume (sample B), $75 \%$ of sample A $+25 \%$ of biodiesel by volume (sample C), $60 \%$ of sample A + 40\% biodiesel by volume (sample D). The results showed that it was possible to significantly increase the flow of emulsions by injecting biodiesel, which was acted as a surfactant, resulting in the lowering of the surface tension of the emulsion sample. The relevance of this research work is validated as it proffers a solution to the transportation of heavy oil and emulsions from all over the world possessing the non-Newtonian flow behavior, which results in serious problems related to its transportation.
\end{abstract}

\section{Keywords}

Emulsion, Biofuel, Flow Enhancement, Pipeline, Additive

\section{Introduction}

Emulsion is a system containing two immiscible liquids such as water and oil. One of the phases of an emulsion system is dispersed as globules in the other. The phase that is present in the form of globules is referred to as the dispersed phase, and the phase that forms the dispersion matrix in which these droplets are suspended is called the continuous phase [1]-[5]. Emulsion droplets generally have a diameter of $0.5 \mu \mathrm{m}$ or larger [6] [7].

Emulsions are used widely across various industries in the present day. Emulsions are widely used across

How to cite this paper: Adesina, F., Paul, A., David, O. and Gbadegesin, A. (2016) Bio-Diesel Based Additive for Enhancing Flow of Emulsion in Pipeline. Advances in Chemical Engineering and Science, 6, 288-293. 
various industries in the present day such as food industry to manufacture day to day products such as milk, cheese, mayonnaise etc.; the paint industry to produce emulsify paints; the pharmaceutical industry to extract and formulate medical products such as hormone products and soluble vitamins; and the cosmetic industry to manufacture products such as creams and lotions among other industrial applications and uses [7]-[9].

In the oil and gas industry, the existence of petroleum emulsions is adequately widespread. Emulsions exist virtually at every stage in petroleum extraction, recovery and industrial processing. This can be seen in specific material such as drilling fluids during drilling, it can also be seen during production and in power plants [6] [7] [9].

Some of the components of crude oil have the ability to form films at oil surfaces, while others are surface active, thus stable and unstable emulsions of different types may exist and vary greatly among different oils.

A good knowledge of transporting emulsions is necessary for controlling and improving processes at all stages. Many studies have been carried out in the last 40 years and have led to a better understanding of these complex systems. However, there are still many unsolved questions related to the pipeline transport behavior of these emulsions. The complexity comes mostly from the oil composition, especially from the surface-active molecules contained in the crude. These molecules cover a large range of chemical structures, molecular weights, and HLB (Hydrophilic-Lypophilic Balance) values; they can interact between themselves and/or reorganize at the water/oil interface [4] [6]. To make the system even more complex these petroleum emulsions may also contain solids and gases which bring about difficulty in the transportation of crude oil and its products due to its water content and high viscosity property, thus these emulations have to be broken down and remade into new emulations to make them suitable for transportation in pipelines to a refinery over a distance (usually long distances).

Another optimal means of transporting crude oil emulsion includes de-emulsification which has positive effect on the flow rate of emulsion but involves series of laboratory experiment to determine the suitability of deemulsifier to achieve this. This process requires expensive resource and does not time.

In 1949, Clark and Shapiro patented a process design for the injection of demulsifying agents mixed with water into pipelines to demulsify crude oil. This was initially an attempt to solve the problem that arose from the injection of only water into pipelines to improve flow, which was found to result to formation of water films inside the pipes.

Traditionally, heating has been used for reducing the viscosity, but it has the disadvantage of significant equipment cost and fuel consumption as well as difficulty in restarting after shutdown [10].

Studies have discovered that under certain conditions, the injection of some fluids such as polymer and surfactant into a crude leads to an alternate reduction in pressure loss, which leads to a positive performance of the fluid flow in the pipelines [1]-[5] [8].

In this research the sample of emulsion was designed, it contained castor oil as the continuous phase and water as the dispersed phase in $80 \%$ to $20 \%$ proportion respectively. The emulsion was then allowed to flow through specially designed piping systems. Flow rates were measured and recorded.

Furthermore, a specially designed and synthesized bio-diesel was injected into the emulsion designed to act as a surfactant. The same process of experiment was carried out again, re-determining the flow rates. Results were derived and conclusions were made.

\section{Aim of Research}

This research aims at solving real life issues. The aim of the research includes:

1) To synthesize biofuel (biodiesel) that would act as a surfactant from algae, which is a non-edible and readily available source.

2) To determine if the injection of the synthesized biodiesel will improve the flow performance during transportation of crude oil emulsions both over vertical and horizontal distances, by breaking down the emulsions into newer and lower viscous emulsions. Also to determine the quantity of bio-diesel that would be providing optimum performance.

3) To proffer an opinion about the practical and economic viability if this research is implemented.

\section{Conduction of Experiment}

\subsection{Experimental Procedure}

\subsubsection{Preparation of Seeds}

1) Dry mature Jatropha Curcas seeds were obtained from Oyo state, south-western Nigeria. 
2) The seeds were peeled and dried further in an oven at about $40^{\circ} \mathrm{C}$ for two hours.

3) The dried seeds were then de-shelled to remove the kernels.

4) The brownish kernels were ground using a grinder (to increase the surface area for the reaction).

\subsubsection{Oil Extraction}

Solvent Extraction using a soxhlet extractor was used in this work to extract oil from the seeds. Hexane was used for the extraction. The collected liquid mixture of hexane and oil was separated via the use of simple distillation; the boiling points of hexane being considerably lower than that of the oil [11].

\subsection{Emulsion Transport in Pipe}

The samples of emulsion for this research were prepared in three distinct compositions, all with $80 \%$ oil and $20 \%$ water emulsified (sample A).

One had $90 \%$ of the already prepared sample A $+10 \%$ of biodiesel by volume (sample B), the second had $75 \%$ of sample A $+25 \%$ of biodiesel by volume (sample C), and the third had $60 \%$ of sample $A+40 \%$ biodiesel by volume (sample D).

The experiment was conducted using the designed apparatus as illustrated in Figure 2.

Samples A, B, C, and D were allowed to flow through the apparatus, a vacuum pump was the pressure source. The samples were placed in a measuring cylinder and pulled through the pipe system at the vacuum end.

As the samples flowed through the apparatus, flow rates per time were determined using a stopwatch.

\section{Apparatus Used}

The apparatus used in achieving results in this research work includes;

Flat bottom flask: This is glassware with a narrow top opening with a flat base. $250 \mathrm{ml}$ flat bottom flask was used.

Round bottom flask: This is also glassware with a narrow top opening but with a round bottom, which usually required a support (usually a heating mantle). $250 \mathrm{ml}$ round bottom flask was used.

Hot plate with magnetic stirrer: This is a heating device that comes with a magnetic stirrer, it was used to agitate the oil mixture in the flat bottom flask on the hotplate.

Thermometer: This is used to measure the temperature of the oil during heating on the hotplate. The thermometer used was graded to $100^{\circ} \mathrm{C}$.

Condenser: This is glassware that is used to cool hot vapor or liquids. It is made up of a large glass tube containing spherical glass chambers running through its entire length within which the hot fluid passes. It was used to cool hexane from vapor to liquid during its separation from the algae oil.

Flat bottom flask: This is glassware with a narrow top opening with a flat base. $25 \mathrm{ml}$ flat bottom flask was used.

Beaker: A beaker is an open container usually used for mixing or storing mixtures or liquids. Beakers are generally cylindrical in shape with a flat bottom. It was used at various stages during this research.

Retort stand: This is common laboratory equipment. It is used to clamp laboratory apparatus and equipment such as beakers, burettes, pipets, separation funnels etc. It was used at various stages during this research.

Soxhlet extractor: This is a laboratory apparatus used to extract lipids from solid materials. It is used when you have a compound that has a limited solubility in a solvent. The soxhlet extractor was used in this research to extract oil from algae.

Burette: This is a graduated glass tube with a tap at one end, for delivering known volumes of a liquid, especially in titrations. It was used during the free fatty acid test during this research.

Pipette: This is a laboratory tool to transport a measured volume of liquid, often as a media dispenser. It was used in several stages of this research work.

\section{Results and Discussion}

The series of tables below show the results derived from the experiment of the flow of the emulsion sample a through the fabricated apparatus (Table 1), the results derived from the experiment of the flow of emulsion plus injected bio-diesel (samples B, C and D) through the same fabricated apparatus (Table 2, Table 3 and Table 4 respectively). 
Table 1. Sample A results.

\begin{tabular}{cc}
\hline \multicolumn{3}{c}{$\begin{array}{c}\text { Experiment on sample A } \\
\text { (80\% oil + 20\% water) }\end{array}$} \\
\hline Viscosity & $146 \mathrm{cp}$ \\
Density & $0.531 \mathrm{~g} / \mathrm{cm}^{3}$ \\
Flowrate & $0.789 \mathrm{~cm}^{3} / \mathrm{s}$ \\
\hline
\end{tabular}

Table 2. Sample B results.

\begin{tabular}{cc}
\hline \multicolumn{2}{c}{$\begin{array}{c}\text { Experiment on sample B } \\
\text { (90\% sample A + 10\% biodiesel) }\end{array}$} \\
\hline Viscosity & $90 \mathrm{cp}$ \\
Density & $0.666 \mathrm{~g} / \mathrm{cm}^{3}$ \\
Flowrate & $3.840 \mathrm{~cm}^{3} / \mathrm{s}$ \\
\hline
\end{tabular}

Table 3. Sample C results.

\begin{tabular}{cc}
\hline \multicolumn{2}{c}{ Experiment on sample C } \\
(75\% sample A + 25\% biodiesel)
\end{tabular}

Table 4. Sample D results.

\begin{tabular}{cc}
\multicolumn{2}{c}{ Experiment on sample D } \\
$(60 \%$ sample A + 40\% biodiesel)
\end{tabular}

This research was aimed at producing or synthesizing biodiesel from a non-edible source that would help break down the emulsion used into lighter or less viscous emulsions. This was successful. Biodiesel was synthesized from jatropha and was injected into the emulsion samples in different volumes resulted in creating less viscous emulsion samples.

Also, this research was aimed at determine if the injection of the biodiesel into the emulsion sample would improve the flow performance. This was also successful as the emulsion sample became less viscous, which made the emulsion need less effort (pressure) to transport it over the same distance.

Complimentary to the aim of determining if the injection of biodiesel to the emulsion sample would improve flow performance, this research also aimed at determining the volume of biodiesel that would act optimally in the improvement of flow performance. This was successful in the approach that was applied. Bio-diesel was added in three different percentages by volume (10\%, $25 \%$ and $40 \%)$.

Figure 1 shows that as the percentage of diesel injected into the emulsion increases the volumetric flow rate of emulsion in pipeline increases until it reaches a maximum at $10 \%$ of biodiesel injected and then decline to point where it steady as the percentage of biodiesel injected continue to increase. This reveals that there is likely optimum ratio in volume of biodiesel to volume of emulsion that is required for optimum rate of emulsion transport in pipe.

Figure 2 shows that increase in ratio of biodiesel in the emulsion decreases the viscosity of emulsion. This evidences that biodiesel can act as surfactant, breaking down the heavy component of emulsion into smaller components, thereby increasing the mobility of emulsion in pipe. 


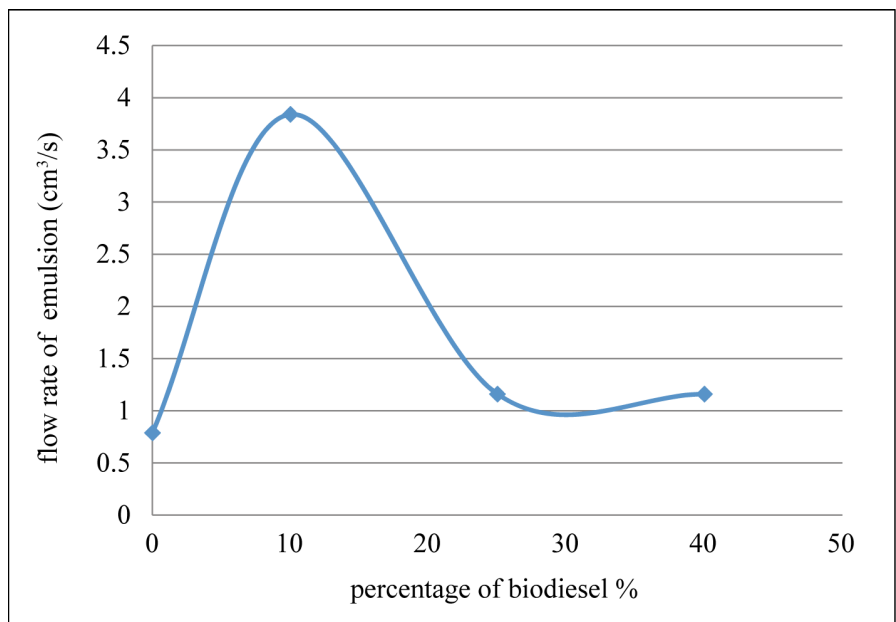

Figure 1. Flow rate of emulsion against percentage biodiesel.

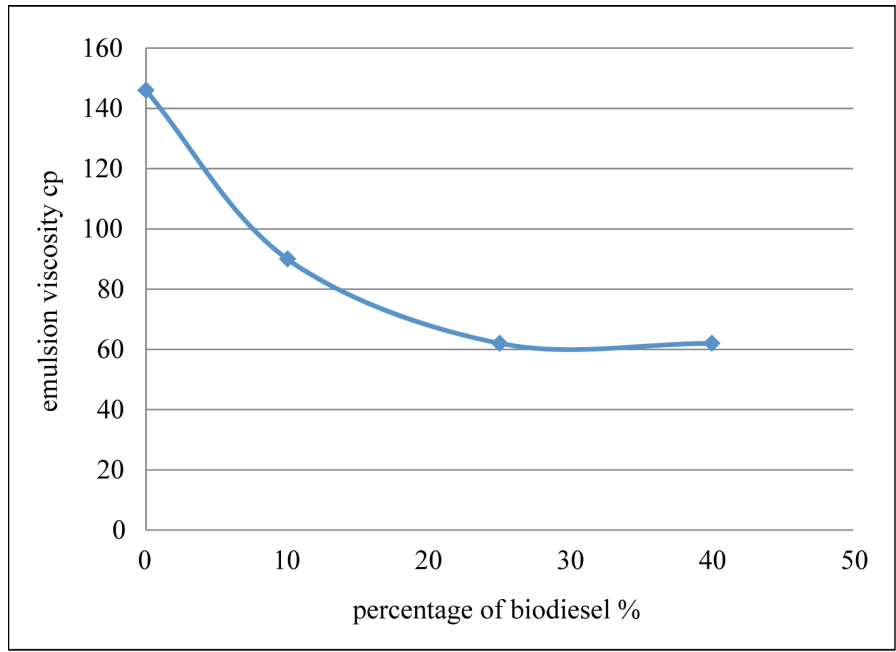

Figure 2. Emulsion viscosity against percentage of biodiesel injected.

$40 \%$ by volume of biodiesel was not exceeded because it would be unrealistic and uneconomical to add biodiesel tending towards half of the volume of the emulsion required to be transported, also the quantity of biodiesel that was synthesized for this research work was not enough to run tests above $40 \%$ by volume.

Amongst the percentages by volume that was used in this research, the sample that had emulsion $+40 \%$ volume of biodiesel had the best flow performance, thus conclusions can be made that all things being equal, the more the quantity of biodiesel injected into the emulsion system, the higher the flow performance.

Finally, this research aimed at proffering an opinion about the practical and economic viability if this research is implemented. The scope of this research was not sufficient to categorically make a call/decision if this research implementation is economically and physically viable. However this research was able to make assumptions guided by the results derived from the experiment that could form the basis of decision making of economic profitability. The assumptions are as follows:

1) Oil exist at constant price.

2) Suction pressure is constant.

3) Specific time interval.

4) The extra cost of biodiesel and additional facilities required for implementation is known.

Given that from the experiment conducted, there is a $93.68 \%$ increase in production within the specified time. Thus ceteris paribus, if the economic value of the total increase in volume (93.68\%) of production is less than the extra cost of biodiesel and additional facilities required for implementation, there would be profitability in 
the implementation of this research, and vice versa.

\section{Conclusion}

Biodiesel injection into emulsion can improve flow performance by acting as a surfactant, breaking the emulsions into lighter and less viscous emulsions. Thus more attention should be paid to the oil and gas industry on better and optimal ways of synthesizing biodiesel in bulk quantities and incorporating the injection process in the process design if there is profitability.

\section{Recommendation}

1) Further research and analysis on this topic should make more research on how to extract more oil from algal samples.

2) After noticing formation of foam in sample B ( $90 \%$ sample A + 10\% biodiesel), a defoamer should be used whenever this occurrence is noticed.

3) Further researchers should find out the key factors that determine the profitability of the implementation of this research into the process of transportation of oil emulsions in the oil and gas industry.

4) Further researchers should put into consideration and vary vital properties in the research such as temperature, and also in apparatus design such as friction factor and pipe roughness.

\section{References}

[1] Arirachakaran S., Oglesby, K.D., Malinowsky, M.S., Shoham, O. and Brill, J.P. (1989) An Analysis of Oil/Water Flow Phenomena in Horizontal Pipes. SPE Production Operations Symposium, Oklahoma City, 13-14 March 1989, SPE Paper 18836, 155-167. http://dx.doi.org/10.2118/18836-ms

[2] Charles, M.E., Govier, G.W. and Hodgson, G.W. (1961) The Horizontal Pipeline Flow of Equal Density Oil-Water Mixtures. The Canadian Journal of Chemical Engineering, 39, 27-36. http://dx.doi.org/10.1002/cjce.5450390106

[3] Guzhov, G., Guzhov, A.I., Grishin, A.D., Medvedev, V.F. and Medvedeva O.P. (1973) Emulsion Formation during the Flow of Two Liquids in a Pipe. Neftyanoe Khozyaistvo, 8, 58-61 (in Russian).

[4] Laflin, G.C. and Oglesby, K.D. (1976) An Experimental Study on the Effect of Flow-Rate, Water Fraction and GasLiquid Ratio on Air-Oil-Water Flow in Horizontal Pipes. University of Tulsa, Tulsa.

[5] Nedler, M. and Mewes, D. (1997) Flow Induced Emulsification in the Flow of Two Immiscible Liquids in Horizontal Pipes. International Journal of Multiphase Flow, 23, 55-68. http://dx.doi.org/10.1016/S0301-9322(96)00055-9

[6] Pal, R. (1993) Pipeline Flow of Unstable and Surfactant Stabilized Emulsions. AlChE Journal, 39, 1754-1764. http://dx.doi.org/10.1002/aic.690391103

[7] Pal, R. (2007) Mechanism of Turbulent Drag Reduction in Emulsions and Bubby Suspensions. Industrial and Engineering Chemistry Research, 46, 618-622. http://dx.doi.org/10.1021/ie061020y

[8] Russell, T.W.F., Hodgson, G.W. and Govier, G.W. (1959) Horizontal Pipelines Flow of Mixtures of Oil and Water. The Canadian Journal of Chemical Engineering, 37, 9-17.

[9] Schramm, L.L. (1992) Emulsions: Fundamental and Applications in the Petroleum Industry. The American Chemical Society, Washington DC.

[10] Zhang, J., Chen, D., Yan, D. and Yang, X. (1991) Pipelining of Heavy Crude Oil as Oil-in-Water Emulsions. Society of Petroleum Engineers, 21733-MS 911-918.

[11] Adesina, F., Anthony, A., Gbadegesin, A., Esseoghene, O. and Oyakhire, A. (2012) Environmental Impact Evaluation of a Safe Drilling Mud. SPE Middle East Health, Safety, Security, and Environment Conference and Exhibition, Abu Dhabi, 2-4 April 2012, SPE-152865-PP. 


\section{Submit or recommend next manuscript to SCIRP and we will provide best service for you:}

Accepting pre-submission inquiries through Email, Facebook, LinkedIn, Twitter, etc.

A wide selection of journals (inclusive of 9 subjects, more than 200 journals)

Providing 24-hour high-quality service

User-friendly online submission system

Fair and swift peer-review system

Efficient typesetting and proofreading procedure

Display of the result of downloads and visits, as well as the number of cited articles

Maximum dissemination of your research work

Submit your manuscript at: http://papersubmission.scirp.org/ 